\title{
THE BUILDING FEATURES ACQUIRED FROM THE INDIGENOUS TECHNOLOGY CONTRIBUTING IN THE BETTER PERFORMANCE DURING EARTHQUAKE: A CASE STUDY OF BHAKTAPUR CITY
}

\author{
Dipendra Gautam
}

\author{
Student Civil Engineering, Khwopa Engineering College \\ Post Graduate Diploma Scholar in Disaster Management, Indira Gandhi National Open University, New Delhi \\ Graduate Scholar in Anthropology, Tribhuvan University
}

\begin{abstract}
:
This paper compiles the indigenous technologies adopted in the Bhaktapur municipality, Nepal in the unreinforced masonry construction of traditional Newari houses constituting more than $90 \%$ buildings in Bhaktapur municipality and their significance during the earthquake. The building units adopted in this area are studied with respect to their performance during earthquake on the basis of seismic resistant design philosophy. The traditionally built non-engineered buildings have drawn the attention of disaster managers for many years; in this regard, the unreinforced masonry buildings (Newari houses) were assessed after the Sikkim-Nepal boarder earthquake of 2011.Still, the buildings constructed before the starting of engineering construction in Nepal are widely used for residential purpose at this culturally rich city and the traditional building construction technology which is the indigenous technology has been practiced for centuries too. The building features are analyzed with respect to their seismic performance and their contribution was analyzed as per the historical database; established practices and theories for earthquake resistant design (EQRD). The collected features and the analyses proved the features of the buildings to be sound during earthquake, though; the buildings were constructed with indigenous technology which nevertheless consults the EQRD within it. The indigenous technology at this city has been attached with the culture of the Newars for centuries.
\end{abstract}

Keywords: indigenous technology, unreinforced masonry buildings, earthquake, Bhaktapur, New ari house

\section{Introduction}

Nepal lies at the top of collision zone of Indian plate and Eurasian plate triggering the tectonic activities and regarded as the most active seismic zone of the world. Ranging from faint tremors to large earthquakes, Nepal suffers from many earthquakes every year due to continuous subduction of Indian plate beneath the Eurasian plate at the rate of $3 \mathrm{~cm}$ per year. Bhaktapur municipality covers 6.88 square kilometers with densely populated Newari settlement and closely constructed buildings.

*Corresponding author: Dipendra Gautam

Khwopa Engin eering College, Purbanchal University

Email: strdyn@yahoo.com

Received: 2013 Jan 02 Accepted: 2013 Mar 06)
Probabilistic seismic hazard mapping of Nepal shows the peak ground acceleration of $0.36 \mathrm{~g}$ in Kathmandu valley in 500 years return period (UNDP, 1994) so the buildings in this region may suffer from destruction during large earthquakes. The Newars from Bhaktapur have adopted some peculiar construction practices through their tradition and experience as indigenous technology. Indigenous knowledge refers to the unique traditional knowledge ex isting within and developed around specific conditions of women and men indigenous to partic sular geographic al area (Grenier, 1998). Indigenous technologies are never documented rather transferred to generations through field practices. More than $98 \%$ buildings in Nepal are found to be constructed by the owners in the advice of the local craftsman (Dixit, 2004), in 
this context the indigenous technology practiced among the communities might be significant in mitigating the earthquake hazards. The traditional Newari settlement of Bhaktapur municipality has adopted peculiar cultural panorama and in this panorama the building construction has achieved an effective indigenous technology as efficient as modern sophistic ated technology or sometimes more effective too. The spacing between the buildings is seldom found so the appearance may lead us to conclude a fragile settlement but during many of the large earthquakes the damage is found to be pretty small one. The loss and destruction during earthquake depend upon many parameters but during this research; indigenous technology is taken as the variant for the earthquake damages. The historical documentation in Nepal has suggested Bhaktapur as earthquake disaster prone area, and destruction at this city might be in big extent (Rana, 1935).

This paper has objective of searching out the earthquake resistant features of the unreinforced masonry buildings regarded as chhen; in milieu of the indigenous technology adopted for centuries at the Bhaktapur Municipality, central Nepal.

\section{Methodology}

\subsection{Field observation}

The field observation of the masonry building was carried out for whole month of February in the core area of Bhaktapur municipality which consists of more than $90 \%$ of its buildings as unreinforced masonry buildings. Every settlement belonging to core area of Bhaktapur municipality was observed.

\subsection{Inte rvie w}

Some of the house owners were interviewed during field observation about their construction practice and the dimensional configuration of building.

\subsection{Photographs}

Most of the technologies adopted in this area are visible except few. So the photographs of the buildings regarding their performance during earthquake were taken.

\section{Results and discussion}

The dynamic and adaptive nature of indigenous technology regarding building construction has remarkably been performed during many earthquakes. The general practice of construction adopted in Bhaktapur is referred to as construction of Newari chhen-house. The Newari Chhen is generally constructed of 3 storied unreinforced masonry building-chhendi-ground floor, mantanfirst floor, chota-second floor and sometimes buigal-terrace. The features of the chhen which have signif ic ant seismic performance are discussed.

\subsection{Building configuration}

Masonry is a specific construction material, which, because of its mechanical properties, requires specific structural configuration even when it is intended to carry only vertical loads. The basic rules for the construction of masonry structures are based on tradition and experience (Tomaževič, 1999). This is regarded as the indigenous technology relating to tradition and experience. A traditional New ari house is dominantly constructed with the help of appa-sun dried bricks with mud mortar as binding reagent. Most of the buildings in the study area were found to be rectangular in configuration. The regular and symmetric configuration adopted as indigenous technology leads the buildings to be stable due to avoidance of torsion in the building. The load bearing walls and the cross walls were found to be unchanging their position and shape along the height of the building and evenly distributed in the building so the torsion is not produced in such building.

\subsection{Dimensions, height and stories of buildings}

The length to breadth ratio of the unreinforced masonry buildings is found to be not exceeding 2 $(\mathrm{L}<2 \mathrm{~B})$; this regards to the avoidance of torsion effect ( $\mathrm{L}>4 \mathrm{~B})$. The height of the building was found to be limited to $10 \mathrm{~m}$ and the storey height is $2.5-3 \mathrm{~m}$ in such buildings. The unreinforced traditional Newari house is of 3 stories; this performs signif ic antly during earthquakes.

Most of the buildings in Bhaktapur municipality are constructed as assembled structures. The traditionally adopted leveling technology leads to 
the prevention of pounding effect during earthquake. The encircled area in Fig 1 shows the connecting portion of two different buildings where the floor level is at same height preventing the pounding effect.

\subsection{Provision of openings}

The unreinforced buildings in Bhaktapur municipality have provis ion of openings as tikijhyadormer window, Sajhya-gable window, and besides this, most of the Newars have business as their profession so they construct the chhendi with the wooden doors. They seldom conduct their business activities in other stories so the higher load intensity is only found in the chhendi. Some of the people

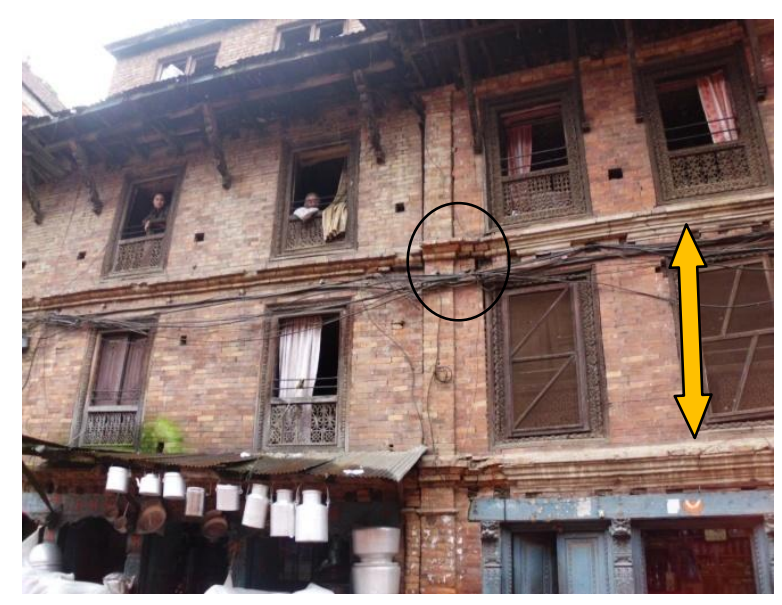

Fig 1 The storey height of building

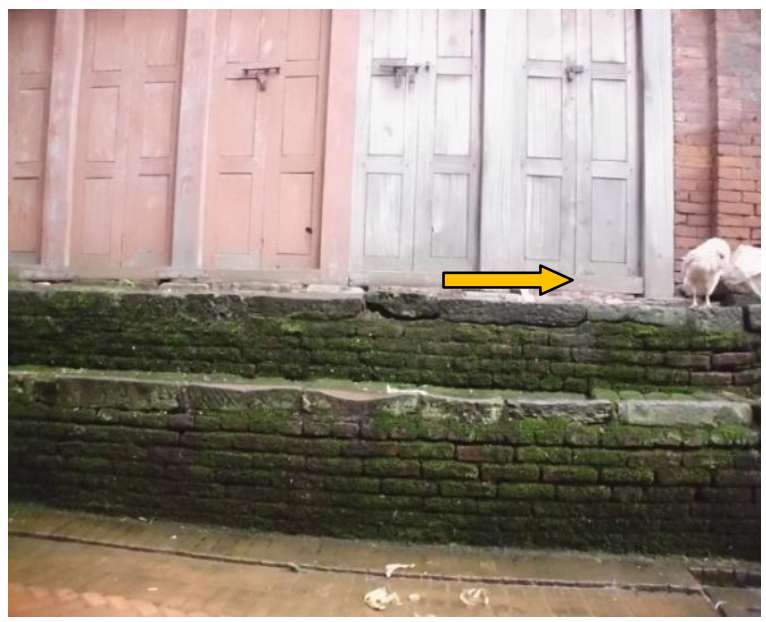

Fig 3 The plinth provided in a build ing conduct their manufacturing industry in the chhendi so the massive load is not caused by the upper stories. The openings in the upper stories are smaller so the stiffness criterion is well met in the traditional unreinforced masonry buildings. The wall of chhendi is found to be provided with 9" thickness and the upper storey walls have thickness of 4.5" hence this ultimately reduces the probability of exceedence of upper storey dead load. Most of the openings were found to be double framed which is taken as significant during resistance of lateral earthquake forces. The small openings in such buildings have their role in preventing soft storey effect thereby assuring stiffness to the structures.

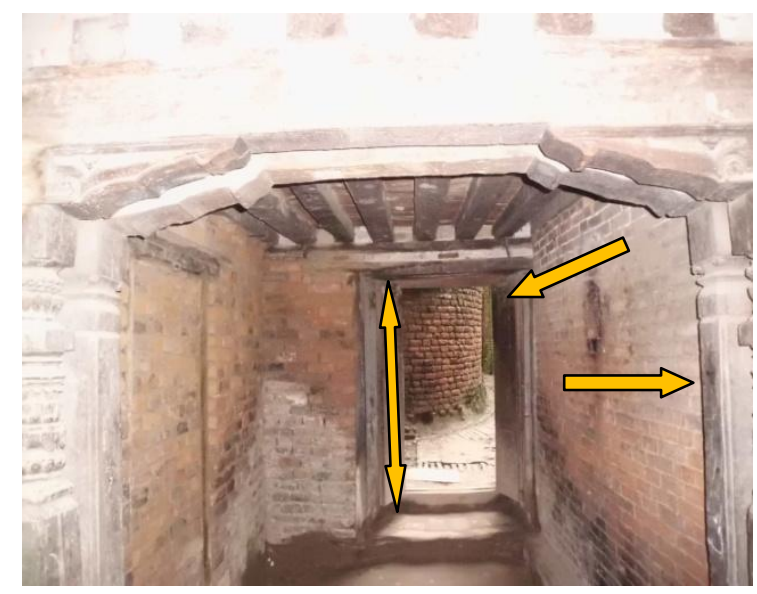

Fig 2 Double framed door openings

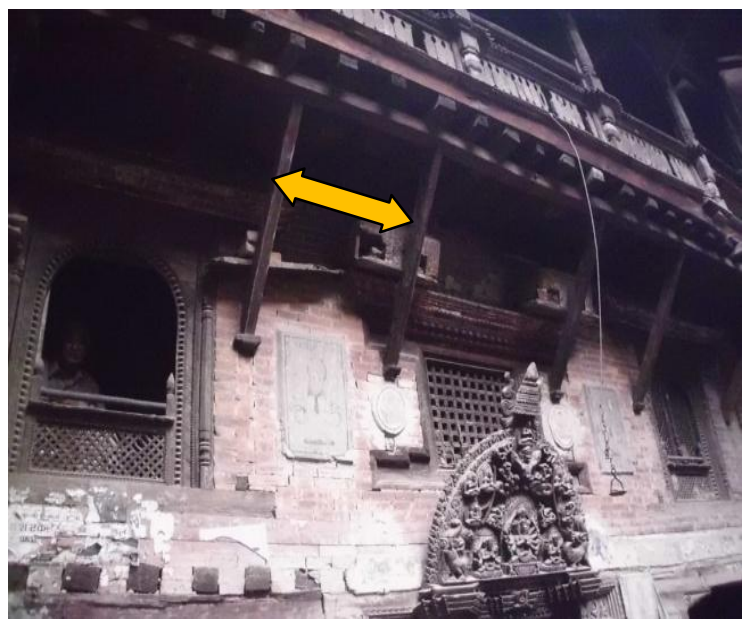

Fig 4 Struts 


\subsection{Plinth}

Most of the historical constructions, and buildings are constructed above a plinth. The introduction of single or multiple plinth leads to improvement of response against wave amplification, and resonance with the ground is avoided. Plinths are extensively used as base isolation means in the indigenous technology by the Newars of Bhaktapur municipality.

\subsection{Struts, wooden pegs and bands}

The struts were found to be provided in the unreinforced masonry buildings. Struts help to transfer the overhanging roof load to the load bearing walls hence the indigenous technology of providing struts has significance in preventing the fall of overhanging roof during earthquake.

The wooden pegs are provided in the traditional unreinforced masonry buildings as the tying members.

The bands at the lintel level and floor level were found to be used in most of the buildings. Those bands converge the building into monolithic unit resisting the earthquake load in joint venture.

\subsection{Non-structural elements}

'Failures or fall-downs of non-structural elements, such as partition walls, chimneys, masonry veneer, ornamentations, etc., might cause casualties and structural damage during strong earthquakes' (Tomaževič, 1999). The indigenous technology adopted in the traditional Newari unreinforced

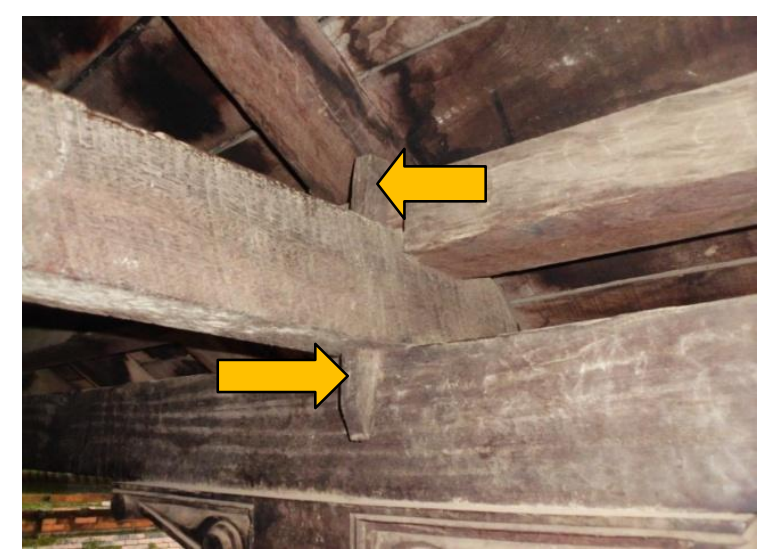

Fig 5 Wooden peg construction has chosen the safe side by implementing the wooden partition wall; which ultimately reduces the dead load of the structure. The wooden ladders with the single flight have considerably less amount of dead load so the damage during earthquake is mitigated in such case. In the indigenous technology adopted in the Bhaktapur municipality; the kitchen is situated in the uppermost storey usually in the chota or even sometimes in the buigal, so the chimney is not provided in Newari houses. This leads to reduction of dead load.

\section{Conclusion}

Nepal suffers from many of the earthquakes every year, so the coping mechanism towards mitigating the earthquake induced hazard is developed from early civilization. The coping mechanisms of disaster risks are well practiced in the indigenous communities. The Newars from Bhaktapur municipality have adopted indigenous technologies since their early construction practice without documenting by the process of hit and trial. The indigenous technologies are transferred to their successors, and it is being practiced hitherto. The construction practices like simple, regular and rectangular building configuration, 3 storied buildings, low storey height, small openings, provision of struts and wooden pegs, wooden bands, low weight non-structural members and plinth in the unreinforced masonry building construction have added fuel reducing the earthquake induced disaster risk in this locality.

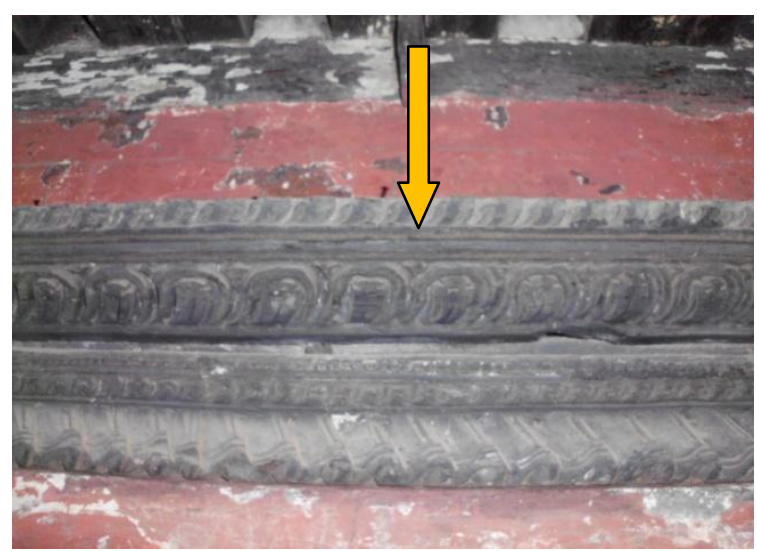

Fig 6 Wooden lintel band 
In doing so, some of the features hinge on the aesthetic aspect of the buildings and others on their belief, tradition, culture and sometimes the religious aspect too. This signifies the transfer of indigenous technology being practiced for centuries without any documentations and enforcements.

"Traditionally made Brick-in-Mud structures are stronger than expected, and they will not generate pancake destruction like (reinforced concrete) RC frame structure. These results lead us to conclude that over $40 \%$ of the traditional masonry remained unaffected in 1934 earthquake, even in the strongly shaken area. Furthermore, the court-yard building with symmetric al shape is considered strong" (JICA, 2004). This interpretation leads to draw the conclusion that indigenous technology is nevertheless the localized and economic practice, rather a technology with scientific basis under the age long experience of hit and trial. The historical evidence presents recommendations on shape, size, build ing materials, workmanship, number of storey, openings, and subsequent load reduction in upper storey after the devastating Bihar-Nepal earthquake (Rana, 1935). Those recommendations might have flourished in the communities so that the indigenous technology has got a platform to be developed as a significant technology regarding the earthquake disaster mitigation.

Nepal, being the area prone to large earthquakes, might suffer from loss of life and property during large earthquakes. Income of people does not correspond to cost of earthquake resistant construction of buildings. The closely constructed structures in Bhaktapur municipality are analyzed with respect to their performance during earthquake and found to be sound with regard to the indigenous technology adopted in building construction with reference to past experience.

\section{References}

[1] Dixit, A.M., 2004. Promoting Safer Building Construction in Nepal, $13^{\text {th }}$ World Conference on Earthquake Engineering. Paper no. 1717, Vancouver, BC, Canada.

[2] Grenier, L., 1998. Working with Indigenous Knowledge: A Guide for Researcher, International Development Center: Ottawa, Canada.

[3] JICA, 2002. The Study on Earthquake Disaster Mitigation in the Kathmandu Valley Kingdom of Nepal.”, a report prepared by Nippon Koei Co., LTD. and Oyo Corporation.

[4] Rana, B.S.J.B., 1935, Nepalko Mahabhukampa [In Nepali], Joreganesh Press, Kathmandu.

[5] Tomaževič, M., 1999. Earthquake-Resistant Design of Masonry Buildings, Imperial College Press, p. 72.

[6] UNDP, 1994. Seismic Hazard Mapping and Risk Assessment for Nepal. His Majesty's Government of Nepal, Ministry of Housing and Phy sical Planning, UNDP/ UNCHS (Habitat) Subproject $\mathrm{NEP} / 88 / 054 / 21.03$ 